Research Article

\title{
Physical Modelling of Roll and Pitch Motions of Travelling or Stationary Ship in Large-Scale Landslide-Generated Waves
}

\author{
Pei-yin Yuan (D), ${ }^{1}$ Ping-yi Wang, ${ }^{2}$ and Yu Zhao ${ }^{2,3}$ \\ ${ }^{1}$ College of Shipping and Naval Architecture, Chongqing Jiaotong University, Chongqing 400074, China \\ ${ }^{2}$ College of River and Ocean Engineering, Chongqing Jiaotong University, Chongqing 400074, China \\ ${ }^{3}$ College of Architecture and Urban Planning, Chongqing Jiaotong University, Chongqing 400074, China \\ Correspondence should be addressed to Pei-yin Yuan; yuan_pei_yin@163.com
}

Received 10 March 2020; Revised 18 May 2020; Accepted 30 June 2020; Published 21 July 2020

Academic Editor: Yanchao Shi

Copyright (C) 2020 Pei-yin Yuan et al. This is an open access article distributed under the Creative Commons Attribution License, which permits unrestricted use, distribution, and reproduction in any medium, provided the original work is properly cited.

Large-scale landslides often occur in river-type reservoirs, and landslide-generated waves affect navigation channels and the navigation of ships. Thus, such waves cause widespread regional disasters. This study establishes a mechanical model of landslidegenerated waves via field investigations and data collection, reveals the mechanism and process of landslide-generated waves, and investigates the propagation characteristics of landslide-generated waves along a sloping wave. The feasibility of the model is verified via (i) regularity analysis, (ii) comparative analysis of the effect of landslide-generated waves of mountain river channel reservoirs on the movement characteristics of navigation vessels and stationary vessels, (iii) deviation from the equilibrium position, and (iv) an in-depth study of the influence of large-scale landslide-generated waves on ships in different navigation positions in a river channel. Countermeasures are proposed for a sailing ship to tackle a sudden landslide-generated wave; these measures can provide a theoretical basis for ships to sail safely through large-scale landslide-generated waves.

\section{Introduction}

Bank slopes are affected by water immersion, water erosion, wave impacts, water level fluctuation, and earthquakes. The unfavourable geological phenomena of high-density rock mass collapse and slip occur frequently, causing large-scale high-density rock mass to move at high speeds. Landslides into water trigger large waves, causing devastating damage to life and property in the landslide area and the surrounding areas. The formation of a landslide-generated wave is generally divided into three stages. In the first stage, the landslide body slides into the water along the bank slope at a high speed and interacts with the water body; then, the water quality points move, and landslide-generated waves are triggered [1]. The second stage is the landslide-generated wave. In the horizontal propagation and diffusion phase of the opposite bank, the propagation phase interacts with structures in the river channel. In the third stage, the landslide-generated wave propagates along the bank slope and offshore [2]. Current research focuses on the characteristics of landslide-generated wave formation and the characteristics of the interaction between landslidegenerated waves and structures.

Recent research efforts into landslide-generated waves have been productive. Heller [3] reviewed existing experiments on subaerial landslide-produced impulse waves. Huang et al. [4] established a source model of landslidegenerated waves in shallow water. Viroulet et al. [5] described extreme events to obtain related scaling laws. YavariRamshe and Ataie-Ashtiani [6] presented a new landslidegenerated wave model to design a granular type of model. Jeevan et al. [7] revealed that the submergence time scaling of distortable two-stage debris significantly differs from that of a nondeformable solid.

Different theories have been utilized to predict ship responses, such as those of Cummins [8] and Hatecke [9], and research efforts into the prediction of ship roll motion have been productive. Liu and Papanikolaou [10] applied a three-dimensional frequency-domain panel code, Ibrahim and Grace [11] studied the impact of large-amplitude ship 
motions and ocean wave loads, and Liu and Papanikolaou [10] presented an online model to predict the roll motion of a ship during manoeuvring. Many researchers also have assessed the navigation safety of ships. Szlapczynski and Szlapczynska [13] presented a way to show data on ship collision avoidance, Yuan et al. [14] proposed a methodology to investigate ship-to-ship safety via the forward speed problem, and Pitana and Kobayashi [15] researched several vessel-related issues regarding pending tsunamis. Chalkias [16] and Tannuri et al. [17] discussed the viability of estimating the on-site directional wave spectrum by measuring stationary ship motion. Some researchers also have begun to propose models of moored ship motion due to the preliminary occurrence of severe tsunamis, such as Uzaki et al. [18], Shigeki and Masayoshi [19], and Sakakibara et al. [20].

This paper is based in part on a large-scale physical model test. The study analyses the results of the model test, derives the empirical formula for the propagation of landslide-generated waves, and compares the characteristics of roll and pitch motions of moving and stationary ships. The conclusions can provide some guidance for the navigation safety of vessels in the Three Gorges Reservoir.

\section{Physical Model}

Although landslide accidents are common, field data from these types of events are unfortunately very limited; such data include rare field measurements of landslide scarp, landslide deposit, tsunami run-up, and eyewitness accounts. Critically important data related to landslide motion and both spatial and temporal tsunami evolution are lacking [21]. Therefore, this paper applies a large-scale model test to collect such data.

2.1. Ship Model. The test vessel was a 3500T river-to-sea container ship. Thin wood was used for the hull plate, various types of wood strips composed the skeleton structure, and the ship model was designed according to a scale ratio of 1:70. Further, geometric, kinematic, and dynamic similarity were satisfied in the design process. Iron weights of differing mass were used to control the different load conditions of the ship, such that the draft, gravity centre position, moment of inertia, and natural period of roll and pitch motion were similar to the prototype. The ship model is shown in Figure 1.

In this test, the ship was assumed to be fully loaded. An MG996R servo was used. Based on the servo motor control theory, the propeller speed could be adjusted to accurately control the ship speed. During the test, we could control the rotation speed of the propeller by controlling the rotation speed of the DC motor. Generally, we used a combination of GPS positioning speed measurement and interval speed measurement, and the navigation speed of the ship model was ensured to be $0.6 \mathrm{~m} / \mathrm{s}$. This paper focuses on two states of the ship: sailing in still water at $0.6 \mathrm{~m} / \mathrm{s}$ and sitting relatively stationary in still water. Table 1 lists all the main parameters of the ship.

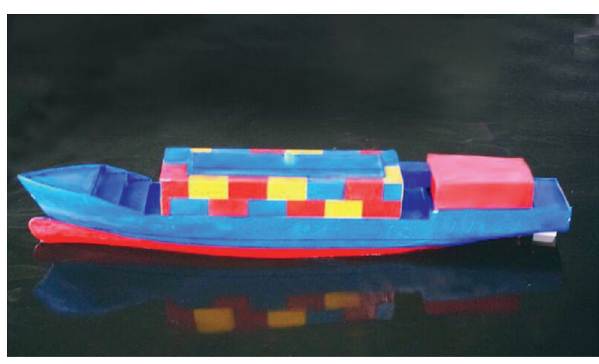

Figure 1: Ship model.

TABle 1: Ship-type parameters.

\begin{tabular}{lcc}
\hline Ship-type parameter & Real ship & Ship model \\
\hline Length of ship (m) & 94.5 & 1.350 \\
Type width (m) & 15.1 & 0.216 \\
Deep (m) & 9.0 & 0.129 \\
Design draught (m) & 5.6 & 0.080 \\
Block coefficient & 0.7 & 0.7 \\
Full load displacement (t/g) & 3500 & 10,150 \\
\hline
\end{tabular}

2.2. Landslide Model. The landslide body was a slider comprising cement, sand, and stone as the raw materials. According to the preliminary investigation and statistics, the landslide body density mortar was reasonably arranged, and different sizes of block moulds were produced. The block body slid along a prefabricated chute comprising ferrous materials. Parameters such as width, height, and inclination were adjustable. The shape of the landslide body was a rectangular parallelepiped. Considering the smaller angle between the direction of action of the landslide body and the water body and the direction of the landslide body, the power of the landslide body on the water body increased, and the landslide inclination angle was selected as $40^{\circ}$ [22]. The length, width, and height of the chute were $1 \mathrm{~m}, 1.5 \mathrm{~m}$, and $0.6 \mathrm{~m}$, respectively. The chute was flexibly affixed onto the carriage. The carriage comprised No. 20 channel steel. The height of the carriage was $2 \mathrm{~m}$, the width was $2 \mathrm{~m}$, and the length was $3 \mathrm{~m}$. The landslide was $1 \mathrm{~m}$ in length, $1.5 \mathrm{~m}$ in width, and $0.2 \mathrm{~m}$ in thickness. The corresponding prototype landslide size was $102,900 \mathrm{~m}^{2}$. The landslide water depth was $0.74 \mathrm{~m}$, corresponding to a water depth of $51.8 \mathrm{~m}$, and the landslide body was symmetrical. During the test, the slider was forced from the water surface along the landslide direction and was accelerated downward at the specified speed in advance. Frictional resistance and external environmental factors such as wind were not applicable during the sliding process. Figure 2 shows the test chute.

2.3. Channel Model. To produce similar physical phenomena for the prototype and the model, the geometric, kinematical, and dynamic similarities must be satisfied. Considering the conditions of the experiment, the scale of the model was selected as $1: 70$, such that the water depth and Reynolds number met the requirements. The channel model was built by the mean of cross section, and the monitoring points were arranged in the channel to set the water level. The cross section is shown in Figure 3. 


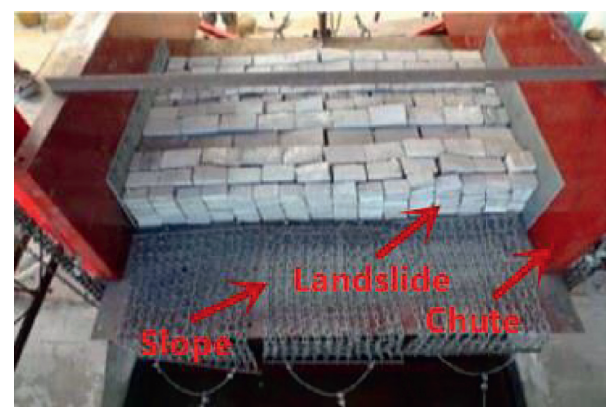

Figure 2: Test chute.

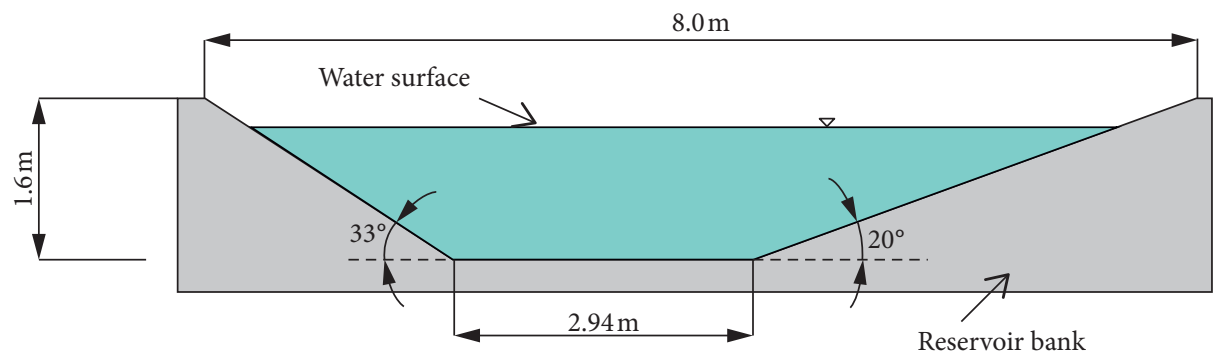

(a)

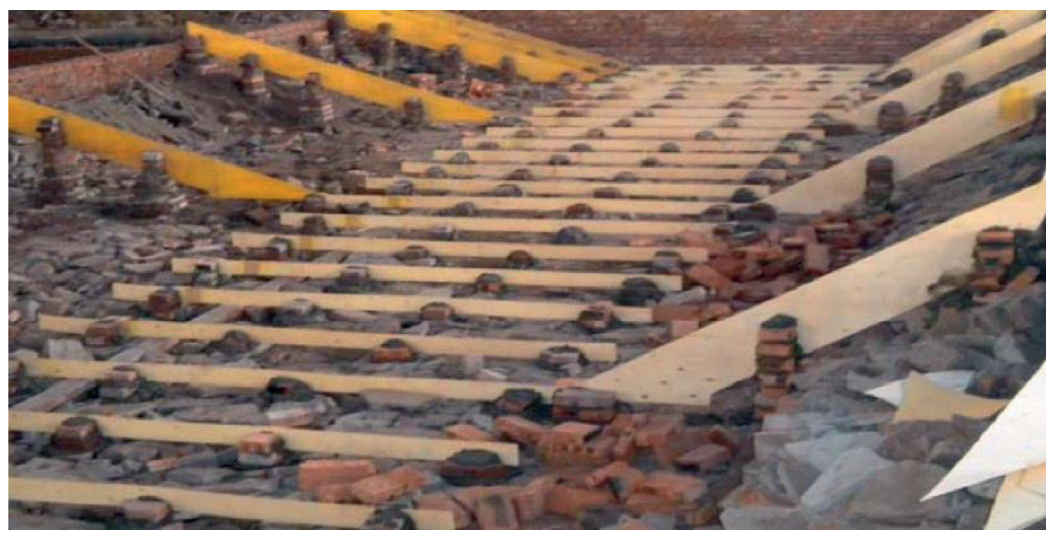

(b)

Figure 3: Cross section. (a) Global diagram. (b) Local diagram.

To monitor the initial height of the landslide-generated wave, the distance between the entry point and collector was selected as $0.5 \mathrm{~m}$. The channel was divided into river course (\#1), landslide water (\#2), and curved water (\#3), as shown in Figure 4.

2.4. Uncertainty in Measurements. System error and random error are the main causes of uncertainty in test measurement. System errors, such as the friction resistance and air resistance of a landslide, cannot be avoided. During the test, after each group of working conditions was tested, the bottom and side of the chute were polished until they became smooth. After the researcher removed the landslide from the river, the chute was dried to reduce the system error as much as possible. In order to reduce the random error, the test was repeated. Four repeated orthogonal tests were conducted for each working condition. Through image recording, it was ensured that the position, length, width, height, and other parameters of the landslide were consistent, and the front end of the landslide at the water interface was readjusted. The first test determined the position of the measurement instrument, and the second test determined the height of the landslide surge. The results of the third and fourth tests were compared. If the resulting error was greater than 5\%, the tests were repeated. If the test result error was less than $5 \%$, the average value of the two groups of tests was taken as the result, to minimize the random error.

2.5. Free Decay Test. When the ship was in still water, the researchers gave the ship a certain roll amplitude and released it smoothly. Through the motion acquisition and analysis device loaded on the ship, the researchers could analyse the ship's roll motion damping and motion law while comprehensively studying the ship's recovery characteristics of freedom in the vertical plane. When the ship deviated from 




FIgURE 4: Channel model and measuring points.

the balance position under the action of external force, if the external force disappeared, the ship either returned or did not return to the original balance position depending on its own recovery characteristics. During the free-attenuation test, the ship model was released when it deviated from a certain angle in still water. The rolling period of the ship model depended on the angle of inclination at the beginning. This test further verified the accuracy of the model. The test results revealed that the amplitude attenuation law of ship roll motion met the test requirements. The hydrodynamic characteristics, natural roll period, roll damping, and inertia moment of the ship could be further adjusted through the free attenuation test. The free attenuation test curve of the ship is shown in Figure 5.

\section{Water Level of Landslide-Generated Wave}

The wave parameters, such as the water level, wave height, and period, were measured. An ultrasonic wave acquisition and analysis instrument designed through independent research and development was used to arrange seven measurement points in the river channel to measure the initial landslide-generated wave height. Monitoring point 1 was the position of the centre point of the landslide body after entering the water. The acquisition time and acquisition frequency were $50 \mathrm{~s}$ and $50 \mathrm{~Hz}$, respectively.

Figure 6 shows a time history curve of the initial wave height after a large volume of landslide body entered the water. The initial waveform of the rock mass landslide was complex, exhibiting random waves with strong asymmetry. After the landslide body accelerated to a slide, the landslide body and water contact area formed a cavity. As shown from the time history curve of the initial wave height, the peak of the initial wave was higher, the trough was lower, and nonlinearity and wave climbing phenomena were obvious. After the peak maximum value, the trough maximum value appeared. The wave amplitude was rapidly attenuated. The maximum wave height of the initial was observed after the landslide body entered the water, and the water body was squeezed to raise the free liquid surface. The energy of the slider was converted to kinetic energy of the surrounding medium, and the vortex strength was attached near the landslide body. The landslide body entered the channel at high speed in the form of a large amplitude wave, and all the energy was released. At this time, the kinetic energy of the water body reached the maximum value; the nonlinearity of the water wave increased and, in turn, suppressed the increase in the peak height of the landslide-generated wave. As time progressed, the landslide-generated wave decayed; the asymmetry of the wave gradually disappeared; and the water surface gradually returned to a stable state. During the model test, the water surface was in a relatively stable state $7.5 \mathrm{~s}$ before the landslide body entered the water. The landslidegenerated wave was transmitted to the monitoring point at $7.5 \mathrm{~s}$. The peak value of the wave was $4.082 \mathrm{~cm}$, and the maximum value of the trough was $1.212 \mathrm{~cm}$. The landslidegenerated wave height and period are shown in Table 2.

\section{Maximum Wave Amplitude and Height}

After the landslide body entered the water, the water surface fluctuated sharply, and the free surface was broken. The degree of fluctuation was related to the width-thickness ratio of the landslide body, the shape of the leading edge of the landslide body, and the shape of the channel. The wave height of the landslide-generated wave was attenuated by analysing the wave height contour of the curved channel, which was divided into four areas: the curve attenuation area, the attenuation area after cornering, the attenuation area within the width of the landslide body, and the attenuation area outside the width of the landslide body. The environmental load considered herein was a ship that was stationary or sailing straight toward the landslide body. The attenuation area within the width range-that is, the section area of the landslide body-met the conditions of a landslide-generated wave.

The height of a landslide-generated wave is affected by the coupling of the initial wave height, water depth, energy exchange adequacy, and river section morphology. Regression analysis was used to determine the empirical calculation formula for the wave height.

This paper primarily considers the propagation characteristics of a landslide-generated wave along the 


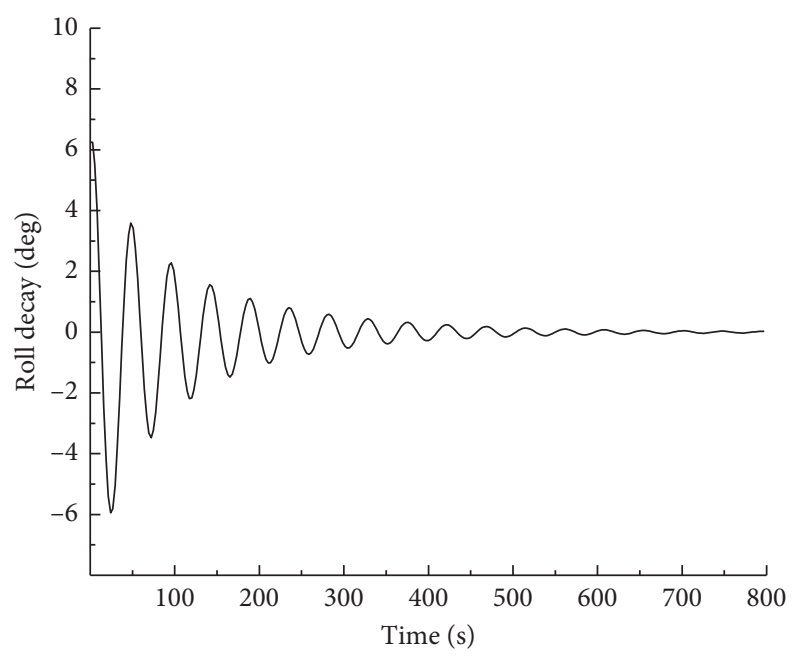

Figure 5: Free decay test of roll.

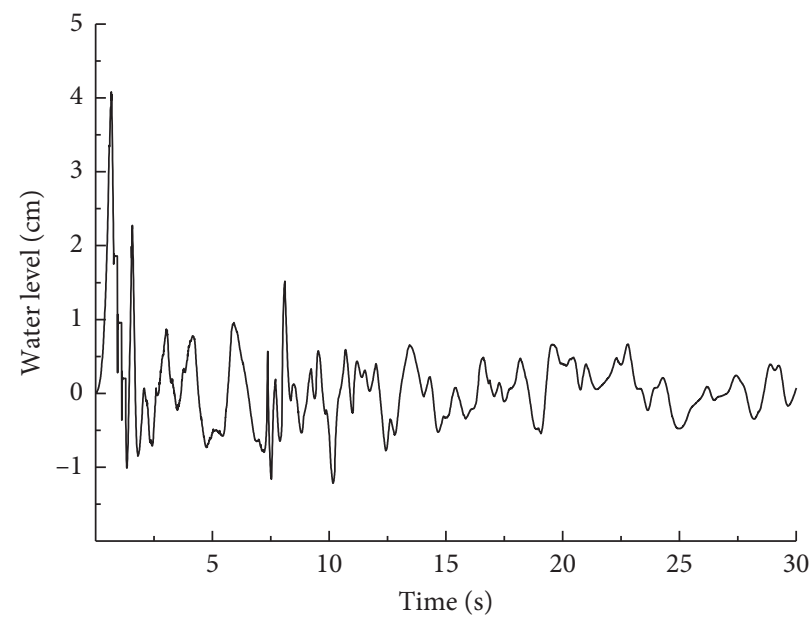

Figure 6: Time history curve of first wave height.

TABLE 2: Initial wave height and period statistics.

\begin{tabular}{lcccc}
\hline Wave number & Maximum wave height $(\mathrm{cm})$ & Effective wave height $(\mathrm{cm})$ & Maximum period $(\mathrm{s})$ & Effective period $(\mathrm{s})$ \\
\hline 35 & 4.082 & 1.870 & 1.028 & 1.023 \\
\hline
\end{tabular}

water inlet section of the landslide body. The primary factors are the initial wave height, the propagation distance $x$, the water depth $h$, and the slip angle. Through a dimensionless analysis of the parameters, the attenuation coefficient of the landslide-generated wave propagation under this condition is obtained:

$$
K=11.94\left(\frac{H_{F W}}{h}\right)^{1.067}\left(\frac{x}{h}\right)^{-0.94} \beta^{-1.23} .
$$

The formula for calculating the wave height is determined by the attenuation coefficient of the power function regression:

$$
H_{a}=K \cdot H_{F W} .
$$

This formula applies to the first wave height in the range of $0-15 \mathrm{~m}$.
By deriving the landslide-generated wave formula along the course, we found that energy loss occurred in the interaction between the landslide body and the water body. As the distance of the landslide-generated wave increased, the wave period increased, the wavelength of the landslidegenerated wave increased, and the wave steepness decreased. Because the same landslide quantity and landslide conditions were applied, the velocities of the landslide-generated waves were fixed, as was the time when the landslide-generated wave reached the ship.

\section{Experimental Result of Landslide- Generated Waves}

The impact of a landslide-generated wave on ship motion is nonlinear, especially for large-scale landslides, which 
produce strong landslide-generated waves. The influencing factors are related to the wave height, period, wave angle of incidence, water depth, and other factors. The ship was stationary or moving at a speed of $0.6 \mathrm{~m} / \mathrm{s}$ in the straight waters, landslide waters, and curved waters. The landslide induced a parameter change. The width of the river model was $8 \mathrm{~m}$, which was generalized to a right-angled curve. The radius of the arc was $7 \mathrm{~m}$, the distance between the navigation position of the ship and the navigation centreline was $0.5 \mathrm{~m}$, the distance between the remote water course and the curved water area monitoring point was $8.94 \mathrm{~m}$ from the landslide entry point, and the landslide water monitoring point was $3.3 \mathrm{~m}$ from the landslide entry point. The monitoring points of the end waters and the curved waters focused on the influence of the shape of the river section on the propagation characteristics of the landslide-generated waves. The monitoring points of the landslide waters were on the landslide section, and the landslide-generated waves were compared to the roll and pitch motions of stationary ships and sailing ships. The law of amplitude variation proposes countermeasures for a sudden landslide by ships and provides certain guidelines for engineering practice. The interaction process between the ship and landslide-induced wave is shown in Figure 7.

\subsection{Experimental Result in Remote Waters of River Course.} Figure 8 shows the effects of the landslide-induced wave in terms of ship roll when the ship was stationary or sailing at a speed of $0.6 \mathrm{~m} / \mathrm{s}$ through the straight waters at the far end of the river. The navigation direction of the ship was opposite to that of the landslide-generated wave. The sailing ship was first subjected to the landslide and then subjected to roll motions owing to the additional ship and quality. Owing to damping, the oblique wave incident angle, reflow, splash, breaking waves, etc., the amplitude of the roll motion of the sailing ship was larger than that of the stationary ship, and the safety factor was low. The rolling motion amplitude of the sailing ship was 5-10 s. A peak was present in each of the 13- to 16-second intervals. Based on research and analysis, the initial direction of rolling is related to wave elements. When a wave crest reaches the ship first, the ship will incline in the direction of wave propagation; when a wave trough arrives first, the ship will incline in the direction of wave propagation. In this process, the landslide-generated waves impacted the hull. No wave was observed on the deck, but a liquid splash occurred. During the landslide, the hull was partially subjected to extreme pressure and the amplitude of the rolling motion. After the occurrence of the peak, the ship gradually settled to a stable state by its own resilience. After the landslide and the hull contact with the wave, the energy of the landslide-generated wave continued to propagate owing to the viscous effect of the water body, and the energy of the landslide-generated wave continued to dissipate. The wave should focus not only on the impact of the sloping first wave on the ship after entering the water but also on the decrease in the ship's roll amplitude. The instant at which the peak of the secondary wave occurred, the ship was still in the water. After the sudden landslide, the amplitude of the rolling motion changed, and the fluctuation range was primarily concentrated at 9-18 s. The variation of the rolling change was strong, and the change in amplitude due to rolling was small. There was no evident liquid splash, but a wave on the deck was observed.

Figure 9 shows the effects of the landslide-induced wave in terms of ship pitch when the ship was stationary or sailing at a speed of $0.6 \mathrm{~m} / \mathrm{s}$ through the straight waters at the far end of the river. The waves exerted fluctuating pressure on the ship, and the amplitude of the pitching motion of the ship changed. The peak value of the pitching motion of the sailing ship occurred at 1-8s. The energy was primarily concentrated during that period, and the maximum pitching motion amplitude was $1.5^{\circ}$. The danger period was high; the ship was stationary in the straight waters at the far end of the river, and the peak value of the pitching motion of the sailing ship occurred at 3-18 s. In that period, the landslide-generated wave had little effect on the ship's pitch, and the maximum pitching motion amplitude was $0.7^{\circ}$; the landslide-generated wave propagated slightly while the ship was sailing, and the ship's navigation direction was opposite to the direction of the landslide-generated wave. A landslidegenerated wave has different impacts on the pitching motion of a sailing ship and a stationary ship. The height of a landslide-generated wave decreases with increasing propagation distance. The wave slams the ship, and the ship's motion response increases over time. The amplitude of motion gradually decreases and eventually becomes stable.

5.2. Experimental Result in Landslide Water. Figure 10 shows the effects of the landslides in terms of ship roll when the ship was stationary or sailing at a speed of $0.6 \mathrm{~m} / \mathrm{s}$ through the waters in the landslide section. Landslides have adverse effects on both stationary ships and sailing ships. Under the continuous action of the original wave, the roll angle reached the maximum value in a short period and then decayed rapidly. Because the applied force and resistance were nonlinear, the attenuation law also was nonlinear. The impact of the landslides on the ships sailing at $0.6 \mathrm{~m} / \mathrm{s}$ was divided into two stages; the first stage occurred within 1-5 s. When the landslide body entered the water, the impact created landslide-generated waves, and the liquid splashed significantly, accompanied by waves on the deck. Because the ship had been sailing straight, the landslide wave acted on the middle and rear parts of the ship. Thus, large-amplitude swaying motion was easily produced, and the rate of change of the motion amplitude was steep. The second stage occurred at 11-18 s and was caused by the landslide-generated wave. The direction was transmitted and finally reached the end of the river, thereby impacting the bank slope, forming reflection, reflow, and superimposing the impact of the synthetic wave on the sailing ship. The maximum amplitude of the rolling motion of the first stage was $10^{\circ}$. The maximum rolling motion of the second-stage ship was $9^{\circ}$. When a ship encounters a landslide in actual 




(a)

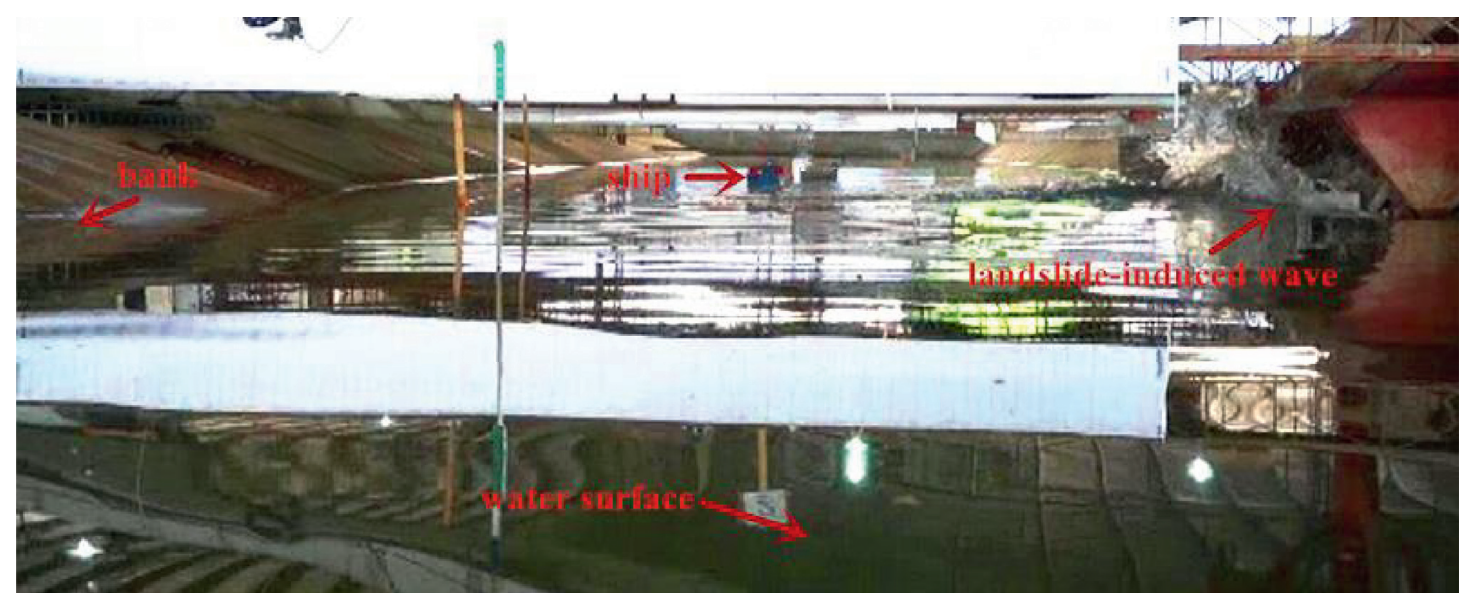

(b)



(c)

Figure 7: Continued.

navigation, it should focus on controlling the navigation speed and instability of the water field to prevent the landslide-generated wave from causing "secondary injury" to the ship. For the stationary ship in the waters of the landslide section, the landslide body generated a landslidegenerated wave after entering the water. The roll motion amplitude of the ship appeared at $1-14 \mathrm{~s}$, showing a single peak state, and the wave energy of the landslide gradually decreased along the landslide. The ship relied on its own recovery torque and recovery damping. The amplitude of the rolling motion gradually decreased and eventually stabilised. The ship was stationary in the sluice waters. It is necessary to focus on the starting moment of the landslide to prevent the landslide from occurring. The impact of the first wave on the 


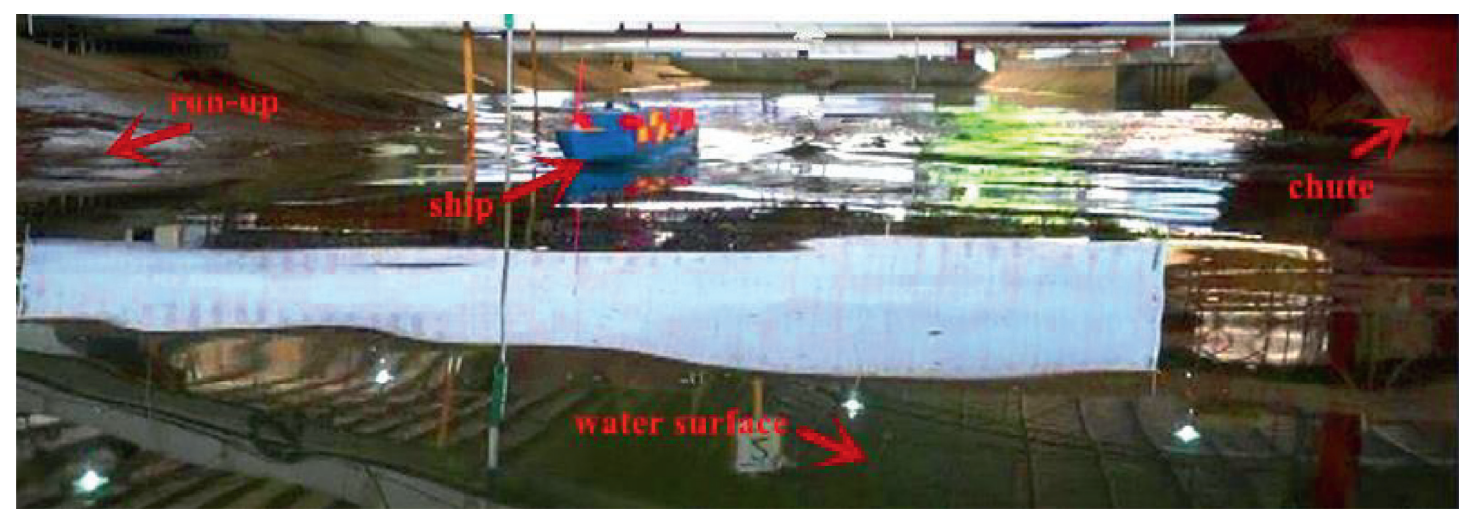

(d)

FIgURE 7: Interaction process between ship and landslide-induced wave.

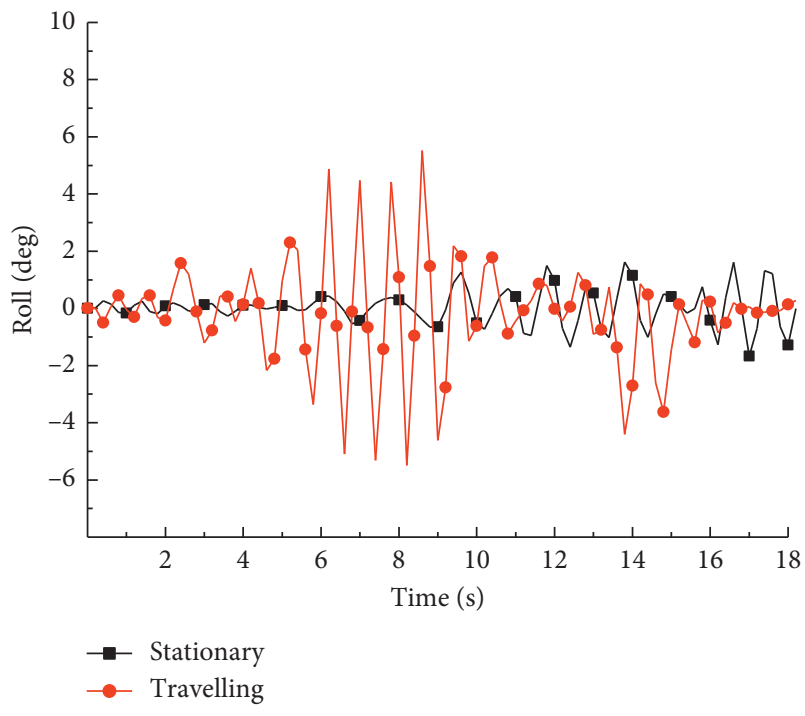

FIgURE 8: Time history curve of ship roll in straight section.

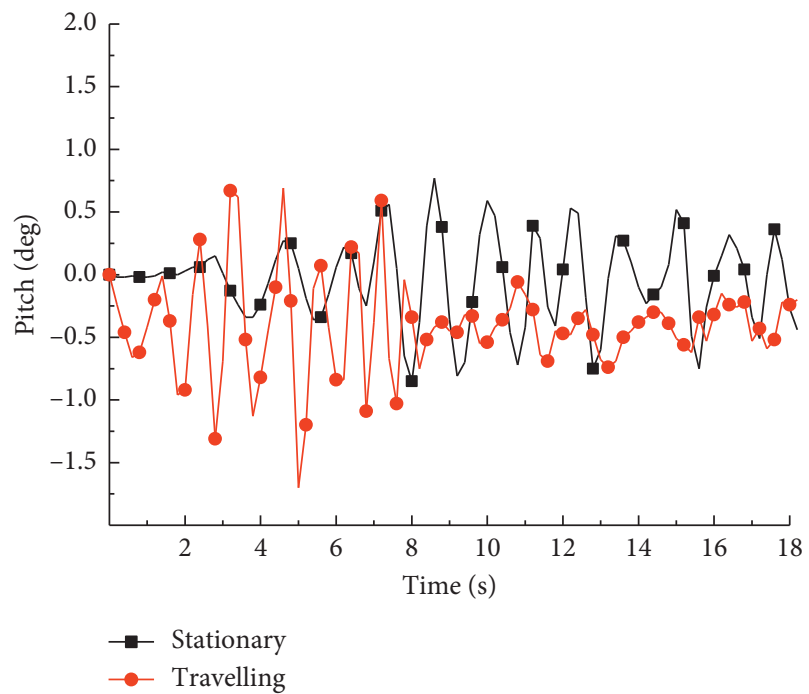

FIgURE 9: Time history curve of ship pitch in straight section.

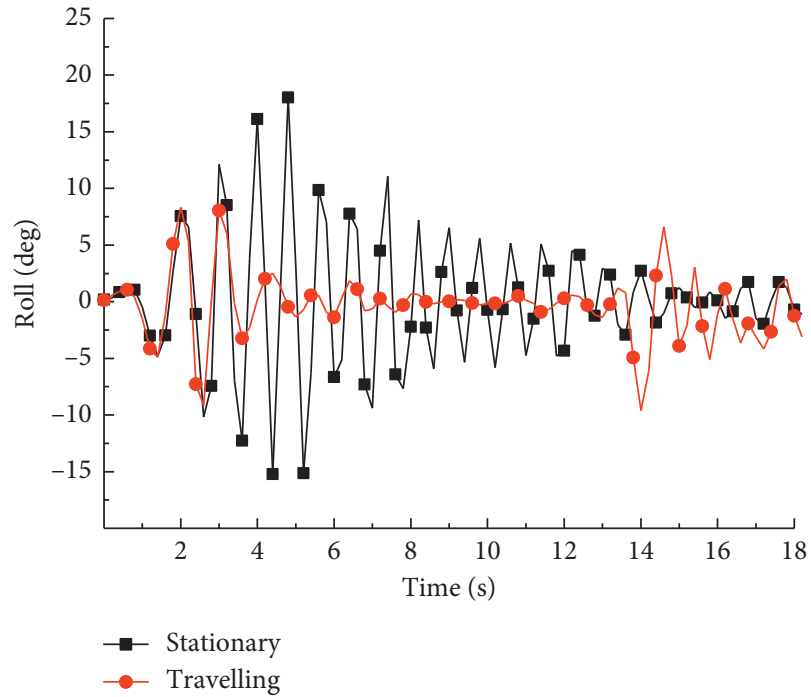

FIGURE 10: Time history curve of ship roll in landslide section.

ship, as well as reasonable and effective disaster prevention and mitigation procedures, should be considered.

Figure 11 shows the effects of the landslides in terms of ship pitch when the ship was stationary or sailing at a speed of $0.6 \mathrm{~m} / \mathrm{s}$ through the waters in the landslide section. The amplitude of the pitching motion of the ship changed, and two large fluctuations occurred. The first fluctuation period was from $0 \mathrm{~s}$ to $5 \mathrm{~s}$. During this period, the landslide body entered the water, and the impulse wave directly interacted with the sailing vessel. The maximum pitch angle was $2.5^{\circ}$; the second fluctuation period was from $13 \mathrm{~s}$ to $15 \mathrm{~s}$. The larger amplitude fluctuation was due to the wave propagation along the path, attenuation, and ship wave. The reflected and diffracted wave superimposed on the wave interaction with the ship, and the maximum pitch angle was $2^{\circ}$. The influence of the rock mass landslide on the stationary ship in the landslide section was consistent with the propagation characteristics of the landslide. Further, the pitch motion amplitude was small: the maximum pitch angle in the still water was $0.5^{\circ}$, and the ship gradually returned to a stable equilibrium state by relying on its own recovery torque. 


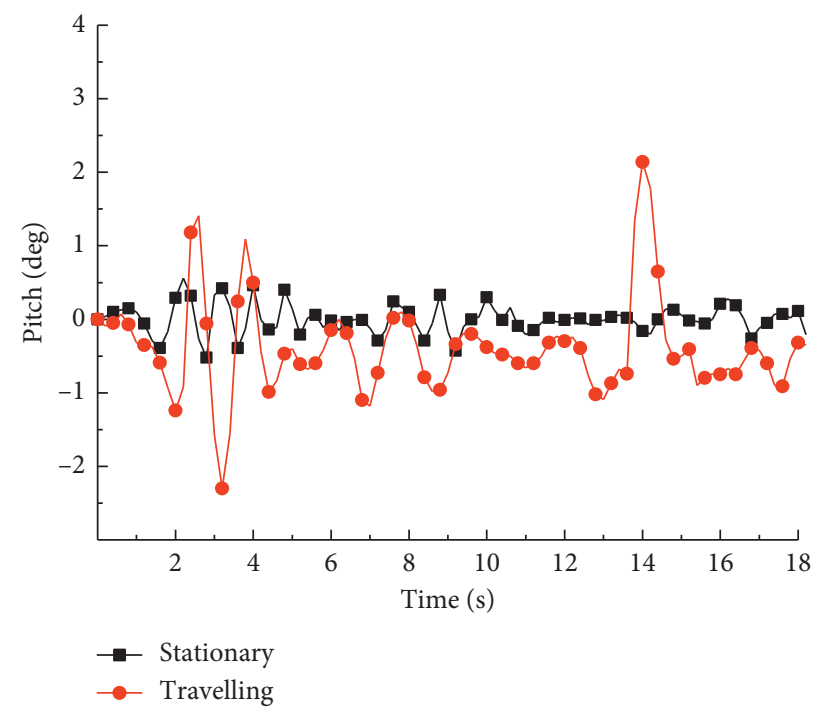

Figure 11: Time history curve of ship pitch in landslide section.

5.3. Experimental Result in Curved Water. A landslidegenerated wave in the river channel is affected by the meandering characteristics of the channel. The speed of the landslide-generated wave caused by the high-speed landslide body was limited, i.e., less than the ship's navigation speed of $0.6 \mathrm{~m} / \mathrm{s}$ and that of the landslide-generated wave. The sailing vessel was in a chasing state and did not influence the ship's motion response amplitude during the measurement time. Therefore, the curved river waters focused the impact of the landslide-generated wave on the motion characteristics of the stationary ship.

Figures 12 and 13 show the results of stationary ships suddenly encountering landslide-generated waves in a curved river. Owing to the influence of landslide-generated waves on curved river channels caused by topography, shore walls, and shallow water, landslide-generated waves show areas of obvious turbulence during propagation, accompanied by strong irregularities and pulses. Under the action of pressure, the stationary ship produced a large-amplitude motion, i.e., the amplitude of the roll motion and the amplitude of the pitch motion. The maximum roll angle was $5.5^{\circ}$, and the maximum pitch angle was $0.9^{\circ}$. After the landslide body entered the water, the first interaction between the first wave and the ship was generated. When the ship was inclined to the left at the beginning, the roll amplitude on the left side of the ship was greater than that on the right side; when the ship was inclined to the right at the beginning, the roll amplitude on the right side of the ship was greater than that on the left side. The landslide-generated waves flowed along the ship climbing, the side waves of the ship, and the forward flow of the ship and continued to spread to the other side. With the gradual reduction in the energy of the landslide-generated wave, the ship's roll motion amplitude and pitch motion amplitude also gradually decreased. The ship relied on its own restoring force and damping and gradually stabilised. In this process, the

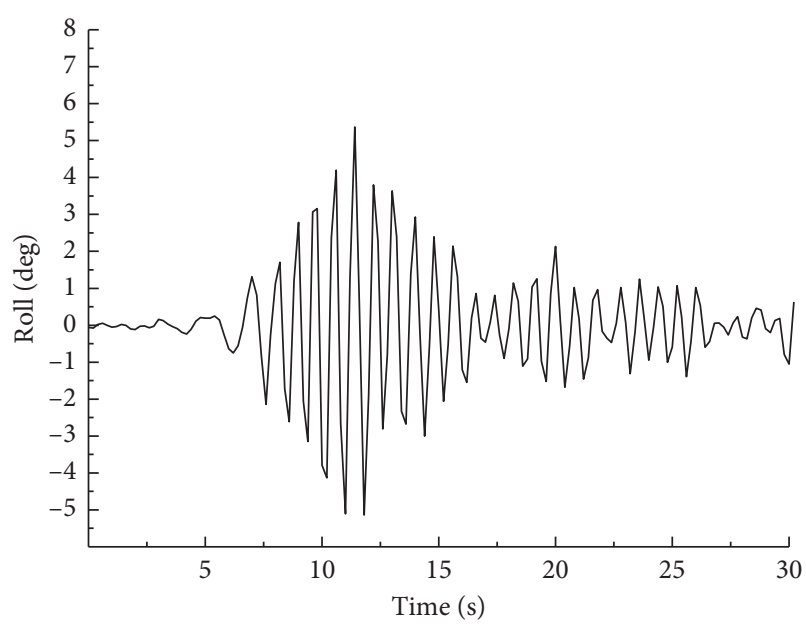

FIgURE 12: Time history curve of ship roll in curved section.



FIGURE 13: Time history curve of ship pitch in curved section. 
ship interacted with the landslide-generated wave. During the process, the phenomena of sloshing and splashing were not obvious. The landslide-generated wave propagated along the same distance, and the influence of the curved channel on the amplitude of the pitching motion of the ship was the same.

\section{Discussion and Conclusion}

Based on collected data, statistical analysis, and on-site measurement of rock mass landslides in the reservoir area, combined with the actual engineering of the navigation channel, a combination of theoretical analysis and physical model tests was used to study the characteristics and spread of landslides in channel rivers. The law and its influence on the amplitude of the motion of stationary ships and sailing ships in the river channel is summarized as follows:

(1) The initial wave of the landslide was a complex wave comprising an undulating wave and an oscillating wave. The height of the first wave of the landslide was directly related to the landslide volume, water inlet angle, and length-to-width ratio of the landslide body. The landslide-generated wave height decreased with increasing propagation distance. The initial wave showed obvious asymmetry; the peak was high, the trough was low, and the nonlinearity was strong. As time passed, the energy of the landslide-generated wave gradually decreased.

(2) The propagation of landslide-generated waves was related to the shape of the river, the distance of propagation, and the depth of the water. The ship sailed at a constant speed in the straight waters, the landslide waters, and the waters in the bends of the river channel. The same type of landslide-generated wave spread to the vicinity of the ship, causing varying degrees of liquid splashing, breaking waves, and backflow. Additionally, the variation in the ship's motion amplitude varied.

(3) If a landslide occurs in the rear of a ship, the ship should accelerate forward to avoid the sluice waters, thus effectively suppressing the peak height and minimizing the landslide with the free attenuation of the landslide energy.

(4) The control of the ship roll angle must be emphasized to prevent a landslide body from entering the water and causing the first wave of the landslide. The incident, reflection, radiation, reflow, and side of the landslide must also be considered. Waves and the slamming of secondary waves responded to the motion of the ship.

(5) To effectively prevent the occurrence of slamming, the design of ships sailing in landslide-affected waters should appropriately increase the deck height and initial clearance to control the shape of the longitudinal section of the ship.

\section{Data Availability}

The data are available in this manuscript. The data in this manuscript were obtained through a series of analyses. The related data used to support the findings of this study are available from the corresponding author upon request.

\section{Conflicts of Interest}

The authors declare that there are no conflicts of interest regarding the publication of this paper.

\section{Acknowledgments}

This study was financially supported by the National Natural Science Foundation (51479015), Social Science and Technology Innovation Program for People's Livelihood in Chongqing (cstc2019jscx-msxmX0302, cstc2018jscxmsybX0233, and cstc2019jscx-lyjsAX0008), and the Science and Technology Program of the Chongqing Education Commission (KJQN201900735).

\section{References}

[1] H. M. Fritz, Initial phase of landslide generated impulse waves, Ph.D. thesis, Eidgenössische Technischen Hochschule Zürich, Zürich, Switzerland, 2002.

[2] P. Yuan, P. Wang, and Y. Zhao, "Model test research on the propagation of tsunamis and their interaction with navigating ships," Applied Sciences, vol. 9, no. 3, p. 475, 2019.

[3] Heller, "Landslide generated impulse waves experimental results," Coastal Engineering, vol. 38, no. 4, pp. 1313-1325, 2008.

[4] B. Huang, S. C. Wang, and Y. B. Zhao, "Impulse waves in reservoirs generated by landslides into shallow water," Coastal Engineering, vol. 123, no. 5, pp. 52-61, 2017.

[5] S. Viroulet, D. Cébron, O. Kimmoun, and C. Kharif, "Shallow water waves generated by subaerial solid landslides," Geophysical Journal International, vol. 193, no. 2, pp. 747-762, 2013.

[6] S. Yavari-Ramshe and B. Ataie-Ashtiani, "A rigorous finite volume model to simulate subaerial and submarine landslidegenerated waves," Landslides, vol. 14, no. 1, pp. 203-221, 2017.

[7] K. Jeevan, P. R. Puskar, K. B. Khattri, P. Kattel, B. M. Tuladhar, and S. P. Pudasaini, "Landslide-generated tsunami and particle transport in mountain lakes and reservoirs," Annal of Glaciology, vol. 57, no. 71, pp. 232-244, 2016.

[8] W. E. Cummins, "The impulse response function and ship motions," Schiffstechnik, no. 9, pp. 101-109, 2010.

[9] H. Hatecke, "The impulse response fitting and ship motions," Ship Technology Research, vol. 62, no. 2, pp. 97-106, 2015.

[10] S. Liu and A. Papanikolaou, "Prediction of parametric rolling of ships in single frequency regular and triple frequency group waves," Ocean Engineering, vol. 120, no. 7, pp. 274-280, 2016.

[11] R. A. Ibrahim and I. M. Grace, "Modeling of ship roll dynamics and its coupling with heave and pitch," Mathematical Problems in Engineering, pp. 242-256, 2010.

[12] J.-c. Yin, Z.-j. Zou, and F. Xu, "On-line prediction of ship roll motion during maneuvering using sequential learning RBF neuralnetworks," Ocean Engineering, vol. 61, no. 6, pp. 139$147,2013$.

[13] R. Szlapczynski and J. Szlapczynska, "A method of determining and visualizing safe motion parameters of a ship 
navigating in restricted waters," Ocean Engineering, vol. 129, no. 1, pp. 363-373, 2017.

[14] Z.-M. Yuan, A. Incecik, S. Dai, D. Alexander, C.-Y. Ji, and X. Zhang, "Hydrodynamic interactions between two ships travelling or stationary in shallow waters," Ocean Engineering, vol. 108, no. 21, pp. 620-635, 2015.

[15] T. Pitana and E. Kobayashi, "Assessment of ship evacuations in response to pending tsunamis," Journal of Marine Science and Technology, vol. 15, no. 3, pp. 242-256, 2010.

[16] D. Chalkias, "Moonpool behavior of a stationary vessel in waves and a method to increase operability," in Proceedings of the ASME International Conference on Ocean, Trondheim, Norway, June 2017.

[17] E. A. Tannuri, J. V. Sparano, A. N. Simos, and J. J. Da Cruz, "Estimating directional wave spectrum based on stationary ship motion measurements," Applied Ocean Research, vol. 25, no. 5, pp. 243-261, 2003.

[18] K.-i. Uzaki, N. Matsunaga, Y. Nishii, and Y. Ikehata, "Cause and countermeasure of long-period oscillations of moored ships and the quantification of surge and heave amplitudes," Ocean Engineering, vol. 37, no. 2-3, pp. 155-163, 2010.

[19] S. Shigeki and K. Masayoshi, "Initial attack of large-scaled tsunami on ship motions and mooring loads," Ocean Engineering, vol. 36, no. 2, pp. 145-157, 2009.

[20] S. Sakakibara, S. Takeda, Y. Iwamoto, and M. Kubo, "A hybrid potential theory for predicting the motions of a moored ship induced by large-scaled tsunami," Ocean Engineering, vol. 37, no. 17-18, pp. 1564-1575, 2010.

[21] B. C. McFall, Physical Modelling of Landslide Generated Tsunamis in Various Scenarios from Fjords to Conical Islands, Georgia Institute of Technology, Atlanta, GA, USA, 2014.

[22] L. Chen, Experimental Study on Characteristics of Rock-type Landslide Surge and Impact for Navigable Conditions of the River-Channel Type Reservoir in Mountainous Area, Chongqing Jiaotong University, Chongqing, China, 2014. 